\title{
Synergism Paradigm and Effective Teamwork Mechanism
}

\author{
Tareq Shareef Younus, Abdulsattar Al-Alusi, Reyaz Ahmad, Mohammad Obaidat
}

\begin{abstract}
The research aims to identify the action aspect of synergy. Although many authors have generated a theoretical clarification to synergy in business area but, still there is no clear measurements addressed in place However, critical review has been conducted in this area of research which suggest that there is a need of performing a significant effort to introduce a measurement technique to quantify the impact of synergism on building an effective teamwork in the workplace. Effective teamwork relies upon synergism that exist among all teams. There are needs of clear analysis to the features that should be identified in order to build up a significant start-up teamwork configuration. This research attempts to identify the factors behind teamwork synergy and the possible consequence of synergism. Research data is generated based on virtual groups, performance. The collection of the research data is based on observations made when virtual workloads were assigned to groups with similar tasks in the field of work. The time factor is one of the variables that the performance results reveal for the specific tasks of the work groups. Mathematical method was used to calculate the latent features which meet the current research propositions. The results of the mathematical calculation were used as an input to further statistical analysis in addition to testing the research hypothesis and to answer the research questions.
\end{abstract}

Key Words: Teamwork, Virtual Performance, Group Formation, Synergy Paradigm, Harmonic Mean, Thematic Analysis, Latent Variable

\section{INTRODUCTION}

The teamwork features considered are the most important indicators for the success of institutional performance as well as teamwork members' interactions.

The synergism concept was linked to many variables with important cognitive connotations. The term teamwork is the most closely related to the concept of synergy.

Slaug \& Björk (2019) provided an important observation regarding an interaction effects as a way of questioning this issue through "when" and "under what conditions" certain kinds of such effects occur. Also, the notion of interaction is in a general sense dependent on the scale with which the exposure effect is assessed (Slaug\& Björk 2019).

Revised Manuscript Received on October 31, 2019.

* Correspondence Author

Tareq Shareef Younus *, American College of Dubai, Dubai- UAE

Email: tareq.younus@acd.ae.

Abdulsattar Al-Alusi, American College of Dubai, Dubai- UAE. Email: abdulsattar.alalusi@aue.ae

Reyaz Ahmad, American College of Dubai, Dubai- UAE. Email: reyaz.ahmad@acd.ae

Mohammad Obaidat, HexaTime LLC, . Email: reyaz.ahmad@acd.ae
It is worth mentioning that the original source of the term synergy is derived from the Greek word synergos, which means "working together." In business terminology, synergy means "the interaction or co-operation of two or more organizations, substances, or other agents to produce a combined effect greater than the sum of their separate effects", Roca-Puig (2019).

Although many extrinsic synergy factors were identified in literature review as major drivers to motivate synergy in an organization, but the intrinsic features are important determinants to activate the synergy application in workplace, Amabile (1993). Intrinsic values, such as passion to work, cooperation oriented attitude, societal worth, results-oriented job, group effective communication, job dedication, ... etc. were rated high significant ingredients for synergy practical implications (Jean, et al (2010). Cohen (1993) presented an idea focused on significant drivers for team effectiveness composed of team performance, employees' attitudes and withdrawals behaviour. González-Romá 2009 stresses the relationships between team climate and team performance, team climate facets extended to include innovation, support and goal achievement Koster \& Bloem (2018).

\section{LITERATURE REVIEW}

Many arguments have emerged in recent years which are focusing on the consequences of teamwork such as synergism and teamwork dynamism. Such consequences have been measured subjectively which provided many subjective judgements to the teamwork effectiveness. However, our research contributes to the on-going scholarly efforts to include the objective perspective which aims to validate the teamwork theme and theoretical framework.

Critical stance has been taken in reviewing relevant literature that highlighted the importance of synergy in assessing the teamwork performance and group work in different organizations. The review map provided rational steps in highlighting the definitions, impact, relationships of relevant concepts of synergy and teamwork/group work concepts. Business dictionary defines the synergy as "A state in which two or more things work together in a particularly fruitful way that produces an effect greater than the sum of their individual effects. Expressed also as "the whole is greater than the sum of parts." Synergy is a term that is most commonly used in the context of mergers and acquisitions. Synergy, or the potential financial benefit achieved through the combining of companies, is often a driving force behind a merger. Shareholders will benefit if a company's post-merger share price increases due to the synergistic effect of the deal. 


\section{Synergism Paradigm and Effective Teamwork Mechanism}

The expected synergy achieved through the merger can be attributed to various factors, such as increased revenues, combined talent and technology, or cost reduction (Amabile 1993).

However, Literature on synergy has provided many definitions to synergy as a system concept which highlighted the collaborative, interactions, knowledge sharing, experience exchange and value added to the group performance (Wagner, et al 2016). Against this background synergy is an objective based calculation of the quality of team performance which should focus on the qualities of team formation based on skills, experience, qualifications, and area of specialization for those who are committed to the assigned tasks by an organization (Larsson \& Finkelstein1999); this need to be elaborated on an inductive approach as to how does this work?

Based on reviewing the literature and current research theme the conceptual model is promoted. Teamwork, on the other hand is linked to the concept of synergy, the concepts presented by many authors focused on team formation and have provided some insights to improve team cooperation, interactions and leadership in the team. The focal point has to build cohesive efforts to reach the intended group goals (Gnizy et al 2016). Through synergism paradigm the team members will learn a new set of skills which mostly generate a foundation to work in different attention (Gallagher et al, 2005). Attention refers to the ability to use mental powers upon tasks and teamwork mission such as careful listening and understanding the teamwork advantage and competition to meet the standards scheduled time line (Gallagher et al, 2005).

Kraus \& Gast (2017) group work based on cooperative intention, team attitude, fair competition and synergy should be supported by a healthy environment; if the teamwork confronted by many obstacles which limit the group work performance the synergy outcome will be affected as well (Jones \& Barry 2011). However, a synergistic and collaborative team should consider in forming a group work instead of just forming groups based on the mechanistic group concept (Silber and others, 2016). In this research, we propose that group work to be formed according to the team spirit for which the objective perspective model is considered.

Consequently, through reviewing literature in this area of research nothing found about how the mechanism of synergy is objectively assessed related to the group performance and achievement. This research sought to create the mechanism for assessing the synergy linked to the different teams and groups work. Synergism in general boost employee's moral, such theme brought forth through the literature review; synergism as a concept associates with teamwork mechanism at workplace. To sustain effective teamwork outcome requires standard features which should be acquired by the team, such rethinking has driven the search for innovative solutions to any designated tasks assigned to the teamwork in business (Gallagher et al, 2005). However, the research model is constructed is shown in figure (1) to reflect research theoretical framework.

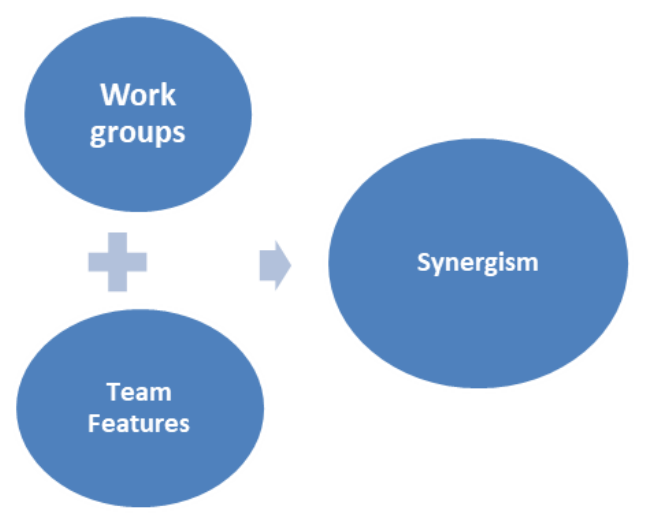

Fig 1. The hypothesized model

\section{RESEARCH METHODOLOGY}

Ontology research approach is used as start-up step in this research methodology. Since the ontology research methodology deals with nature of reality and a system of belief which reflects an interpretation by an individual about what constitutes a fact. The research will conceptualize potential outcomes of an analysis on the relationship among research dimensions (Vogl, et al, 2019), (Gallagher et al, and 2005).

Moreover, thematic analysis being used as theoretical and interpretative frameworks to conceptualize the qualitative context of synergism. It is compatible with phenomenological approaches which we addressed in this research that are behind synergy theme there are many interrelated teamwork members' features which are all qualitative in nature (Braun et al 2018). This view being capitalized on the quantitative analysis and that result in a statistical parameters. In this context the research methodology is expected to generate new insight to the teamwork- synergism attitude in the workplace.

\section{A. Participants and data generating}

Two virtual groups have been taken for the research as samples for generating data. Similarities in group assignments have been considered. The groups have granted the researchers to have an access to their performance and outcome. Observations for fifteen paired teams have been chosen. The total number of observations thus becomes $(2 * 15=30)$ (Krejcie \& Morgan, 1970). A threshold of 32 hours has been assigned to both groups as a standard score.

\section{B. Research contribution}

Our study contributes to the literature in the following ways:

- Exploring the time line synchronization if any among the observed teams.

- Analyzing the gap if any among teams performance.

- Conceptualizing the harmonic corporate efforts based on synergistic paradigm.

- Identifying the role of latent factor in teamwork harmony. 
- Refinement attempt to confirm that teamwork passion including relevant features is behind effective group performance to the designated tasks.

\section{Research Problem}

The topic of synergism and its association with many other areas of science is one of the largely studied topics by the scholars in the past and still being studied. Scholars show different reasons as to why synergism has been an issue of many planners and managers. One of the reasons is that the features of synergism behavior has become a factor that has direct impact on the overall performance of the effective teams. However, the main questions are as follows:

- How the groups or business community should leveraging the standards of group work performance?

- How synergy factor influences the outcome of group work performance?

- Does latent variable contributes to harmonic team performance?

- Which group (set of teams) met the threshold standard timeline or otherwise?

\section{Research Hypothesis}

It is worth mentioning that the research is exploring the influence of synergism theorem on activation of a corporate and collaborative codes of actions in teamwork performance. Based on the literature review and research theoretical model, we hypothesize:

Hypothesis 1: Latent factor stands behind synergism action of teamwork mission achievement.

Hypothesis 2: All the sample means are not equal and they have a significant differences

\section{E. Research Validity and Reliability}

Comprehensive discussion with the colleagues who have deep knowledge, experience and skills in math's, statistics and management area of specializations were made. The discussion helped in confirming the face validity for the research tools and measurement. Their views also led us to prepare the query tool in generating research data.

The Cronbach alpha coefficient for the two observed groups' items is $87 \%$ as in table (1) which suggests that the items have relatively high internal consistency.

\section{F. Strategy Analysis}

To test the proposed expected model relationship we performed descriptive statistics that summarize a given data set. This can be either a representation of the entire or a sample of a population. In our research approach the descriptive statistics used were the measures of central tendency and measures of variability.

Table (1)

\section{Reliability Statistics}

\begin{tabular}{|c|c|}
\hline Cronbach's Alpha & N of Items \\
\hline .870 & 2 \\
\hline
\end{tabular}

G. Results

\section{- Descriptive results}

The findings presented in table (2) provide clear gaps between groups time span in each individual group and between both groups. The mean and SD for group1 (47.87) and SD (16.12392), whereas for the group 2 mean (48.73) and standard deviation (14.14449). The gap is slightly different in the mean and standard deviation, but the individual team performance provided differences.

In this condition the research identifies the rationale behind such differences between each teams time taken to complete the task and the given estimated threshold time of 32 hours to achieve the designated mission.

\section{Table 2: Descriptive Research Observed Data for both} Groups (*) Scores by Hours

\begin{tabular}{|c|c|c|}
\hline Groups & Group 1 & Group 2 \\
\hline 1 & 22 & 28 \\
\hline 2 & 33 & 45 \\
\hline 3 & 38 & 46 \\
\hline 4 & 30 & 44 \\
\hline 5 & 58 & 45 \\
\hline 6 & 52 & 61 \\
\hline 7 & 36 & 38 \\
\hline 8 & 67 & 55 \\
\hline 9 & 40 & 43 \\
\hline 10 & 74 & 78 \\
\hline 11 & 66 & 69 \\
\hline 12 & 45 & 35 \\
\hline 13 & 34 & 33 \\
\hline 14 & 67 & 46 \\
\hline 15 & 56 & 65 \\
\hline Mean & 47.8 & 48.7 \\
\hline SD & 16.1 & 14.1 \\
\hline
\end{tabular}

(*) Group means the set of teams.

Furthermore data description includes both arithmetic means and harmonic means which are used as measures of the central tendency. The Harmonic mean has broad implications for the analysis of large datasets which enhances the potential for scientific discovery in such cases (Wilson, 2019). Nevertheless, calculations were generating additional primary data which the research is using for further statistical analysis.

Latent variable is included in our research to use it as start up for synergism concept. The synergy is not observed as physical item in the qualitative measurements. The team work is grand name for the interactions sets of variables such as team members' passions to work and cooperate, skills, experiences, loyalty, respect rules, team vision awareness, and sincerity, commitment, accepting challenges, time management skills, effective communication among group work and many other criterion.

However, the interrelation, among team members in action and their mission fulfilments could not be detected. 


\section{Synergism Paradigm and Effective Teamwork Mechanism}

The only way to reach the teamwork achievement and outcome is in meeting the timeline target that is specified by the management based on rational measurement standards. The reflection of the latent variable in such interaction, we refer them as the synergy theme action in place. In table (3) the latent variable is the result of smoothing differences between harmonic mean and arithmetic mean. The results have shown slight differences but this is an important outcome for further analysis. It needs careful manipulation as causal relationship in team network interactions (Bollen, 2014). The latent variable is a hidden variable that is not directly observed but is rather inferred through a mathematical

Calculations based on other variables that are observed and measured.

Table (3)

\section{Harmonic and Arithmetic means records}

\begin{tabular}{|c|c|c|c|c|c|}
\hline & Grou & Grou & Harmon & Arithme & Latent \\
\hline & 22 & 28 & 24.64 & 25 & 0.36 \\
\hline & 33 & 45 & 38.08 & 39 & 0.92 \\
\hline & 38 & 46 & 41.62 & 42 & 0.38 \\
\hline & 30 & 44 & 35.68 & 37 & 1.32 \\
\hline & 58 & 45 & 50.68 & 51.5 & 0.82 \\
\hline & 52 & 61 & 56.14 & 56.5 & 0.36 \\
\hline & 36 & 38 & 36.97 & 37 & 0.03 \\
\hline & 67 & 55 & 60.41 & 61 & 0.59 \\
\hline & 40 & 43 & 41.45 & 41.5 & 0.05 \\
\hline & 74 & 78 & 75.95 & 76 & 0.05 \\
\hline & 66 & 69 & 67.47 & 67.5 & 0.03 \\
\hline & 45 & 35 & 39.38 & 40 & 0.62 \\
\hline & 34 & 33 & 33.49 & 33.5 & 0.01 \\
\hline & 67 & 46 & 54.55 & 56.5 & 1.95 \\
\hline & 56 & 65 & 60.17 & 60.5 & 0.33 \\
\hline Av & & & & & \\
\hline SD & 16.1 & 14.14 & 14.30 & 14.27 & 0.55 \\
\hline
\end{tabular}

The findings in table (3) provide clear insight to address the thematic analysis which generates relevant theoretical frame of reference to proceed for further rectification to the synergism outcome in quantitative parameters. The research suggests to compute the deviation and record it.

The deviations in column (3) and column (5) of table-4 being calculated using the following formula in Table (4 as below):

Deviation $=\mathrm{T}(1$ or 2$)$ (value) $\mathrm{X}$ (Standard deviation) of the latent variable $(=0.55)$

This calculation applied to all other teams' actual performances, then to reach the difference of the average deviations that occurred from the time threshold assigned to fulfil the teamwork assignment. This gives the existence of synergism that is taking place in the performance of the two groups.
Table (4) Deviations among teams

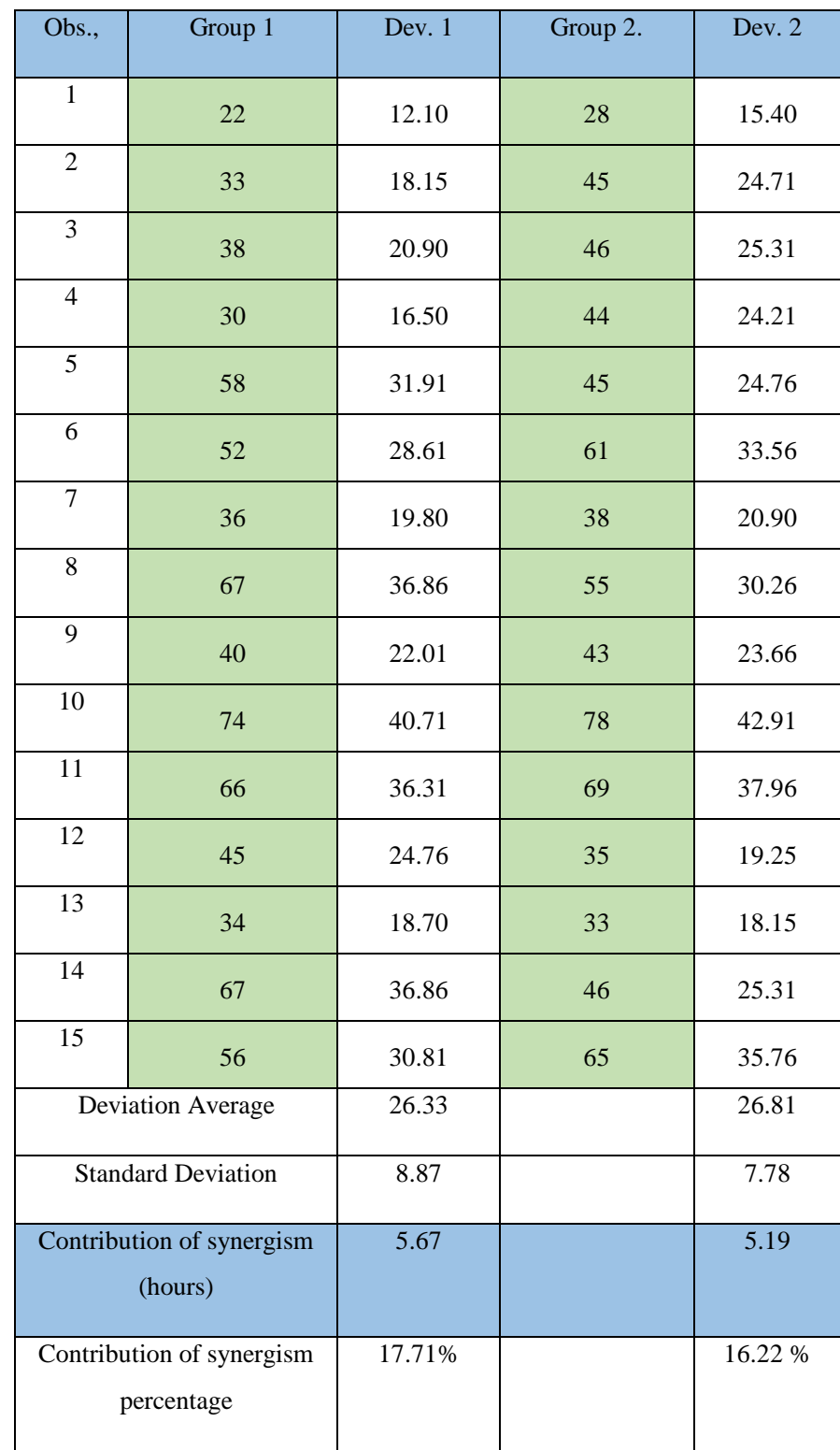

The results of deviations average in both teams have provided slight differences. The average of deviations of group (1) is (26.33) and that of the group (2) is (26.81). Since all results are positive it implies the existence of synergism. It existed as a qualitative indicator to define the teamwork mechanism behavior through fulfilling their designated mission.

The standard deviations for the group (1) and group (2) are (8.87) and (7.78) respectively. This also shows a slight differences between the two groups.

However synergism theme has contributed positively, because targets were seen to be achieved in time lesser than the designated threshold time. The contributions of synergism as shown, in the above table are (5.67 average hours for group 1) and (5.19 average hours for group 2). This indicates a percentage contribution of group (1) as $(17.71 \%)$ and that of the group (2) as (16.22\%).

This means that the team formation is done by considering the features of the team work in place to fulfill the designated mission. 
Ultimately, the findings have provided that (H1) Latent factor stands behind synergism action of teamwork mission achievement, and thus, the null hypothesis is rejected.

\section{- Inferential analysis results}

Further to the fact that synergy is almost thematically addressed by the descriptive statistic made, it encouraged us to go for an inferential analysis. The research sample and generated data have met the conditions to go for the t-test as an inferential statistical analysis. The research assumed that there is a significant difference between the means of two observed set of the groups compared to the estimated standards hours of (32 hours). The analysis outputs using SPSS software are in tables ( $5 \& 6)$. The reference of the research preposition is based on the logic of synergism theme which denotes to certain team formation features. The t-test is one of many tests used for the purpose of hypothesis testing in statistics.

Table (5)

\section{One-Sample Statistics}

\begin{tabular}{|l|r|l|c|c|}
\hline & \multicolumn{1}{|c|}{$\mathrm{N}$} & Mean & $\begin{array}{c}\text { Std. } \\
\text { Deviation }\end{array}$ & $\begin{array}{c}\text { Std. Error } \\
\text { Mean }\end{array}$ \\
\hline Group1 & 15 & 47.8667 & 16.12392 & 4.16318 \\
Group2 & 15 & 48.7333 & 14.14449 & 3.65209 \\
\hline
\end{tabular}

The above table presents the mean values for both groups in the research as (47.87) and (48.73) for group one and group two respectively. The corresponding standard deviations provided are (16.12) and (14.14) respectively. The standard errors of the means for both groups are (4.16) and (3.65) respectively.

Table (6)

\begin{tabular}{|c|c|c|c|c|c|c|}
\hline \multicolumn{7}{|c|}{ One-Sample Test } \\
\hline & \multicolumn{6}{|c|}{ Test Value $=32$} \\
\hline & \multirow[b]{2}{*}{$\mathrm{t}$} & \multirow[b]{2}{*}{ df } & \multirow{2}{*}{$\begin{array}{l}\text { Sig. } \\
\text { (2-taile } \\
\text { d) }\end{array}$} & \multirow{2}{*}{$\begin{array}{c}\text { Mean } \\
\text { Difference }\end{array}$} & \multicolumn{2}{|c|}{$\begin{array}{c}\text { 95\% Confidence } \\
\text { Interval of the } \\
\text { Difference }\end{array}$} \\
\hline & & & & & Lower & Upper \\
\hline Group1 & 3.811 & 14 & .002 & 15.86667 & 6.9375 & 24.7958 \\
\hline Group 2 & 4.582 & 14 & .000 & 16.73333 & 8.9004 & 24.5663 \\
\hline
\end{tabular}

The mean difference values for group one is (15.87) and the mean difference for group two is (16.73). Through this difference we conclude, that group one have practiced synergism theme more than the group two. This observation confirms the conclusion that we made in the descriptive analysis. However, the calculated $(\mathrm{t})$ value is (3.8) for group one and (4.58) for group two and both of these values are in the range of significant value of (0.05). Thus, both of these results prove that the hypothesis (2) "all the sample means are not equal and they have a significant difference". This differences are in favour of synergism theme.

\section{CONCLUSION}

Synergism is a widespread theme needed in different organizations. It is a time wise hub and a competitive advantage element in highly organized organizations.

The current research is characterized by presenting the idea of standardization of the synergy as a term and as an action.

The concept of synergy is linked to working as a team. Where the term team in the field of work has importance in terms of management expectations when planning to accomplish specific tasks and within standard duration of time.

While it is rare to find clear criteria for measuring the synergy in the research on this subject, the current research initiated the introduction of an exploratory approach to the standardization of synergism.

The current research provides an introduction to the analysis of the elements in an ontological framework as well as its integration into the quantitative framework. This research produced the data according to the observations and virtual estimates of the work groups. The aim is to be precise in providing the requirements of exploratory research in the field of the synergism, which includes monitoring the latent variable that is not visible.

Research initiatives are the simulations of the theoretical concept of the virtual reality in which the team lives. It is to be noted that providing a team with specific specifications is the mainstay of reaching the goals of the synergy.

From this point of view, data were processed according to the logic of descriptive statistics and deductive statistics. Conclusion of the research confirms the achievement of the synergy of the working groups.

The research results in a qualitative-quantitative analysis of the statistical evidence that there is possibility to standardize the synergy. Thus it can possibly be used in decision making of differentiation between the team that met the synergy estimates as well as the value added time to outstanding achievement. This research with an original results and synchronized analysis will open new avenue to furthering the path of synergism theme.

\section{REFERENCES}

1. Amabile, T. M. (1993). Motivational synergy: Toward new conceptualizations of intrinsic and extrinsic motivation in the workplace. Human resource management review, 3(3), 185-201.

2. Bollen, K. A. (2014). Structural equations with latent variables (Vol. 210). John Wiley \& Sons.

3. Braun, V., Clarke, V., Hayfield, N., \& Terry, G. (2018). Thematic analysis. Handbook of research methods in health social sciences, $1-18$.

4. Cohen, S. G. (1993). Designing effective self-managing work teams. Centre for Effective Organizations, School of Business Administration, University of Southern California.

5. Gallagher, A. G., Ritter, E. M., Champion, H., Higgins, G., Fried, M P., Moses, G. \& Satava, R. M. (2005). Virtual reality simulation for the operating room: proficiency-based training as a paradigm shift in surgical skills training. Annals of surgery, 241(2), 364.

6. Gnizy, I., Shoham, A., \& Asseraf, Y. (2016). Does Firm Strategic International Orientations Synergize? In Let's Get Engaged! Crossing the Threshold of Marketing's Engagement Era (pp. 677-678). Springer International Publishing.

7. González-Romá, V., Fortes-Ferreira, L., \& Peiro, J. M. (2009). Team climate, climate strength and team performance. A longitudinal study. Journal of Occupational and Organizational Psychology, 82(3), 511-536. 


\section{Synergism Paradigm and Effective Teamwork Mechanism}

8. Jean, L., Bergeron, M. È., Thivierge, S., \& Simard, M. (2010). Cognitive intervention programs for individuals with mild cognitive impairment: systematic review of the literature. The American Journal of Geriatric Psychiatry, 18(4), 281-296.

9. Jones, J., \& Barry, M. M. (2011). Exploring the relationship between synergy and partnership functioning factors in health promotion partnerships. Health Promotion International, 26(4), 408-420.

10. Koster, F., \& Bloem, D. (2018). "Have a little faith" A vignette study of inter-organizational cooperation and innovation performance. Int. Journal of Business Science and Applied Management, 13(1).

11. Koyawala, N., Silber, J. H., Rosenbaum, P. R., Wang, W., Hill, A. S., Reiter, J. G., ... \& Nazarian, S. (2017). Comparing outcomes between antibody induction therapies in kidney transplantation. Journal of the American Society of Nephrology, 28(7), 2188-2200.

12. Kraus, S., Schmid, J., \& Gast, J. (2017). Innovation through coopetition: An analysis of small-and medium-sized trust companies operating in the Liechtenstein financial centre. International Journal of Business Science \& Applied Management (IJBSAM), 12(1), 44-60.

13. Krejcie, R. V., \& Morgan, D. W. (1970). Determining sample size for research activities. Educational and psychological measurement, 30(3), 607-610.

14. Larsson, R., \& Finkelstein, S. (1999). Integrating strategic, organizational, and human resource perspectives on mergers and acquisitions: A case survey of synergy realization. Organization science, 10 (1), 1-26.

15. Roca-Puig, V. (2019). The circular path of social sustainability: An empirical analysis. Journal of Cleaner Production, 212, 916-924.

16. Slaug, B., Iwarsson, S., \& Björk, J. (2019). A new approach for investigation of person-environment interaction effects in research involving health outcomes. European journal of ageing, 16(2), 237-247.

17. Vogl, S., Schmidt, E. M., \& Zartler, U. (2019). Triangulating perspectives: ontology and epistemology in the analysis of qualitative multiple perspective interviews. International Journal of Social Research Methodology, 1-14.

18. Wagner, G., Schramm-Klein, H., \& Steinmann, S. (2016). The Role of Synergy and Complementarity in a Multichannel E-Commerce System. In Looking Forward, Looking Back: Drawing on the Past to Shape the Future of Marketing (pp. 661-661). Springer International Publishing.

19. [19] Wilson, D. J. (2019). The harmonic mean p-value for combining dependent tests. Proceedings of the National Academy of Sciences, 116(4), 1195-1200.

\section{AUTHORS PROFILE}

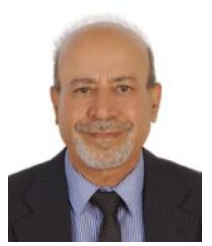

\section{First Author Tareq Shareef Younus}

$(*)$

American College of Dubai

Dubai- UAE

Email: tareq.younus@acd.ae

Tel: +971508965575

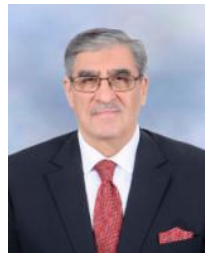

Second Author Abdulsattar Al-Alusi

American University in the Emirates

Dubai- UAE

Email: abdulsattar.alalusi@aue.ae

Tel: +971506903329

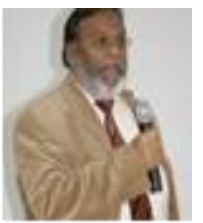

Third Author Reyaz Ahmad

American College of Dubai

Dubai- UAE

Email: reyaz.ahmad@acd.ae

Tel: +971504484219

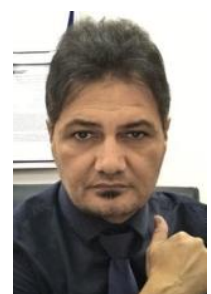

Fourth Author Mohammad Obaidat HexaTime LLC

Email: drmohdobeidat@bus.illinois.edu Tel: +962790402205 